\title{
Nem Tui, nem Gibraltar: Óláfr Haraldsson e a Península Ibérica
}

\author{
Neither Tui, nor Gibraltar. Óláfr Haraldsson and the Iberian \\ Peninsula
}

\author{
Helio PIRES \\ Instituto de Estudos Medievais, Universidade Nova de Lisboa \\ heliovpires@sapo.pt
}

Recibido: $25 / 04 / 2014$

Aceptado: 17/06/2014

\section{RESUMEN}

Según la Heimskringla, Óláfr Haraldsson, rey y santo patrón de Noruega, navegó hasta el Estrecho de Gibraltar. Se afirma que ganó varias batallas a lo largo del viaje, algunas de las cuales han sido localizadas en Galicia. Incluso hay quienes dicen que Óláfr fue el responsable del saqueo de Tui, por lo que sabemos esta noticia gracias a un documento gallego de 1024. Al fin y al cabo, ¿qué existe de veracidad en esta teoría? Y, ¿hasta qué punto la narración sobre el viaje del santo noruego es fidedigna? El siguiente artículo se centra en estas cuestiones, presentando una respuesta basada en el análisis de fuentes nórdicas, particularmente en el proceso de transmisión del poema Víkingarvísur. Se destaca la necesidad de leer separadamente las narraciones poética y en prosa, el silencio de los textos ibéricos y la dimensión ideológica presente en las sagas de los reyes, llegando a la conclusión de que Óláfr non fue más allá de los Pirineos.

Palabras clave: Óláfr Haraldsson, Vikingarvísur, Heimskringla, Tui, Noruega, vikingos.

\begin{abstract}
According to Heimskringla, Óláfr Haraldsson, king and patron saint of Norway, sailed to the Straits of Gibraltar. It is told that he won several battles along the journey, some of which have been placed in Galicia. There are even those who say that Óláfr was responsible for the looting of Tui, which appears in a Galician document from 1024. But how much truth is there in that theory? And how far can one trust the narrative on the journey of the Norwegian saint? The following article focuses on these questions, proposing an answer based in the analysis of the Norse sources, namely the process and context of transmission of the poem Víkingarvísur. It highlights the need for the poetic and prose narratives to be read separately, the silence of the Iberian texts and the ideological dimension found in the kings' sagas, leading to the conclusion that Óláfr may not have travelled beyond the Pyrenees.
\end{abstract}

Key words: Óláfr Haraldsson, Víkingarvísur, Heimskringla, Tui, Norway, Vikings

Sumário: 1. A questão. 2. As fontes. 3. As narrativas. 4. Quando. 5. Onde. 6. O rei santo. 7. Conclusão. 


\section{A QUESTÃo}

Nos capítulos 17 e 18 da Saga de São Olavo, parte da colectânea de sagas de reis conhecida como Heimskringla, é-nos dito que Óláfr Haraldsson, à época ainda futuro rei e santo padroeiro da Noruega, atacou vários locais numa viagem que o levou de Inglaterra até junto do Estreito de Gibraltar, onde ele acabou por voltar atrás ${ }^{1}$. A localização exacta das incursões nunca é referida, mas o facto de serem mencionadas entre a partida de Inglaterra e a chegada de Óláfr à entrada do Mediterrâneo tem levado sucessivos autores a localizarem pelo menos alguns dos topónimos na Península Ibérica. A ideia faz certamente sentido do ponto de vista geográfico e, pelo menos desde o século XIX, a hipótese indicada por Adam Kristoffer Fabricius sobre a identidade dos locais atacados tem sido mais ou menos seguida por diversos autores. É o caso, por exemplo, de Almazán e Morales Romero. Aliás, é quase um lugar comum dizerse que Óláfr Haraldsson atacou Tui ou que passou pela Galiza, de tão frequente que é a ideia em publicações sobre a presença dos piratas nórdicos na Península Ibérica. Mas o que há, afinal, de verdade nessa tese? $\mathrm{E}$ até que ponto os textos medievais permitem-nos dizer que aquele que viria a ser rei e santo padroeiro da Noruega esteve, de facto, em território ibérico?

\section{AS FONTES}

Correndo o risco de dizer o óbvio, qualquer resposta a perguntas sobre acontecimentos no período medieval deve assentar em informação da época e o mais contemporânea possível. Só assim podemos ter uma ideia minimamente sólida sobre o que se passou e evitar o erro de concluir uma coisa apenas porque outros estudiosos o disseram. Como tal, para respondermos às perguntas sobre a viagem de Óláfr Haraldsson, devemos, em primeiro lugar, perceber quais as fontes de informação disponíveis, o que dizem elas ao certo e quais os aspectos críticos a ter em conta.

O relato mais antigo é o do poema Víkingarvísur do islandês Sigvatr Pórðarson, datado do século $\mathrm{XI}^{2}$. Do autor, sabe-se que foi poeta na corte de Óláfr Haraldsson, tendo mesmo desempenhado o papel de embaixador do monarca numa viagem à Suécia ${ }^{3}$. Quanto à composição, conhecem-se quinze estrofes, uma delas incompleta, não havendo certezas quanto à dimensão original do poema. Também não se sabe ao certo como é que foi preservado até ao século XIII, o que é um problema geral da poesia skáldica, género em que se insere o Víkingarvísur. Pode ter sido registado por escrito, dado que há vestígios arqueológicos que apontam para a preservação de trabalhos poéticos nesse formato ${ }^{4}$. Mas é igualmente possível que tenha sido transmitido oralmente, processo que seria facilitado pelas complexidades da métrica skáldica, por um lado favorecendo a memorização e, por outro, dificultando grandes alterações ao

\footnotetext{
${ }^{1}$ Heimskringla, pp. 257-8.

2 Disponível online na base de dados do Skaldic Poetry Project: http://abdn.ac.uk/skaldic/m. $\mathrm{php}$ ? $\mathrm{p}=$ text $\& \mathrm{i}=1360$

${ }_{3}$ Jesch, Ships and Men, p. 89.

${ }^{4}$ Frank, "Skaldic Poetry", p. 175.
} 
poema sem causar o seu colapso estrutural. Independentemente do modo de preservação, se oral ou escrito, acresce ainda a dúvida sobre se a transmissão foi integral ou parcial. Neste aspecto, as opiniões dividem-se entre os que propõem uma preservação integral até à fragmentação dos poemas pelos autores das sagas, a partir de c. 1200, e os que sugerem uma transmissão parcial em que excertos dos relatos poéticos foram transmitidos juntamente com pequenas narrativas em prosa, as quais interpretavam ou desenvolviam o conteúdo das estrofes ${ }^{5}$. Também não é impossível que os diferentes formatos tenham coexistido, com registos escritos e prosimetra orais a circularem em simultâneo pela Escandinávia. Seja qual for o caso, importa reter que o Vikingarvísur é mais antigo do que a Saga de São Olavo contida na Heimskringla, o que quer dizer que esta não é um texto unitário e coerente, escrito num dado momento pelo mesmo autor. Aliás, conforme referido por Roberta Frank, as estrofes skáldicas e a prosa das sagas nem sempre coincidem no relato que fazem ${ }^{6}$, o que sugere não só uma diferença cronológica, mas também a necessidade de ler separadamente as duas narrativas.

Outra fonte a ter em conta é a Historia Norwegie, escrita em latim talvez por volta de 1165 e provavelmente na Noruega ${ }^{7}$. Tem apenas uma referência muito breve à viagem de Óláfr Haraldsson, no capítulo $18^{8}$, mas é uma obra de algum valor para uma análise crítica, até pelo enfoque que tem na formação do reino norueguês. Por fim, há ainda duas outras fontes nórdicas, ambas do século XIII e colectâneas de sagas de reis: o Fagrskinna, datado de cerca de 1225 e de autor desconhecido, e a já referida Heimskringla, escrita por volta de 1230. A autoria desta última é, por norma, atribuída a Snorri Sturluson, embora sem certeza ${ }^{9}$, sabendo-se apenas que a obra foi em parte redigida com recurso a histórias e poesia que, segundo o prefácio medieval, era usada para entretenimento e que o autor considerava fidedigna desde que correctamente interpretada ${ }^{10}$. O que, por um lado, é sintomático da forma como os autores das sagas encaravam os poemas enquanto fonte de informação e, por outro, remetenos de volta ao tema da preservação da poesia skáldica, nomeadamente o papel dos contadores de histórias na transmissão das composições ou de prosimetra.

Quanto a fontes ibéricas, não se conhece nenhum registo da presença de Óláfr Haraldsson na península. É verdade que há notícias de investidas nórdicas nas primeiras décadas do século XI, mas nenhum dos textos diz quem liderava os grupos de piratas. Temos apenas uma coincidência cronológica que nos permite resumir a três os ataques potencialmente liderados pelo, à época, futuro rei da Noruega: a pilhagem da região entre os rios Douro e Ave em 1015 e 1016, registada num documento três anos posterior ${ }^{11}$; o assalto ao castelo de Vermoim, de que ficou notícia na Crónica dos Godos ${ }^{12}$; e, por último, a referência ao saque e abandono de Tui, acontecimento

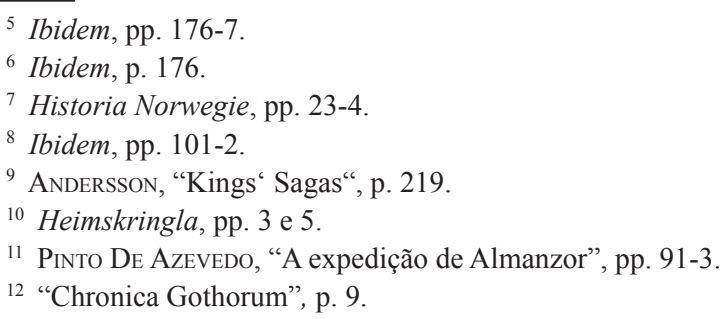


para o qual não nos é dada uma data concreta, restando-nos apenas o terminus ante quem de 1024, data do documento preservado no Tombo A da Catedral de Santiago de Compostela ${ }^{13}$.

São estas as fontes de que dispomos para perceber o que aconteceu no início do século XI e quais, se alguns, foram os locais atacados por Óláfr Haraldsson na Península Ibérica. Com as questões críticas em mente, é da análise destes e doutros relatos que nos devemos ocupar de seguida.

\section{AS NARRATIVAS}

Depois de referir uma batalha num local chamado Nýjamóðu, talvez situado em Inglaterra, a estrofe 10 do Vikingarvísur regista aquele que diz ser o décimo combate de Óláfr, que teve lugar em Hól. O topónimo é normalmente identificado com o Dól, na Bretanha, interpretação reforçada pela História dos Duques Normandos, de Guilherme de Jumièges, onde é referido que Ricardo II da Normandia recrutou um homem chamado Olavus, líder de um exército de pagãos que tomou o Dól ${ }^{14}$. Parece por isso possível que Óláfr Haraldsson tenha estado no norte de França, mas a narrativa poética torna-se menos clara a partir deste ponto.

Depois do Dól, diz a estrofe 11 que a batalha seguinte ocorreu num local chamado Gríslupollr, supostamente diante da propriedade de um Viljálm ou Guilherme (Viljalms fyr bœ). Segue-se o décimo segundo combate, de acordo com a meia estrofe com o mesmo número, onde é dito que Óláfr combateu em Fetlafjöror, enquanto a secção seguinte do poema situa a décima terceira batalha em Seljupollr, referindo ainda a captura de um nobre chamado Geirfiðr, senhor de uma fortificação que recebe o nome de Gunnvaldsborg. Dado que a cada estrofe corresponde um confronto militar, é possível que o nobre tenha sido aprisionado no seguimento da batalha em Seljupollr, mas enquanto este e os outros topónimos que se seguem ao Dól são difíceis de localizar, a estrofe 14 volta a dar-nos referências familiares: Leiru ou o rio Loire, em França, e ainda Peitu ou Poitou. Ou seja, não só as estrofes conhecidas do Víkingarvísur não fazem qualquer referência a Gibraltar, como os topónimos identificáveis estão situados em território francês. O que nos permite fazer a seguinte pergunta: deverão todos os locais entre Gríslupollr e Gunnvaldsborg ser também eles localizados em França?

A questão não se põe se lermos as sagas de reis, uma vez que tanto a narrativa em prosa do Fagrskinna como a da Heimskringla colocam Óláfr Haraldsson no sul de Espanha. À semelhança do poema, a primeira das duas colectâneas refere a décima batalha, localizando-a em Holi, seguindo-se os mesmos topónimos que no Vikingarvísur e a referência a Geirfiðr ou Geirfinnr, para usar a forma registada no Fagrskin$n a^{15}$. Até este ponto, a narrativa em prosa coincide com a poética e embora não seja citada qualquer estrofe, mas depois o texto diz-nos que Óláfr Haraldsson navegou até um sítio chamado Karlsáróss, que seria um rio ou, em rigor, a foz de um rio, dado o elemento -óss, que identifica precisamente a desembocadura de um curso ou massa

\footnotetext{
${ }^{13}$ Lucas Álvarez, Tumbo A, pp. 152-4.

14 The Gesta Normannorum Ducum, pp. 24-7.

15 Fagrskinna, p. 135.
} 
de água. Segue-se o desejo de atravessar o Estreito de Gibraltar, a ausência de vento favorável e, por fim, a revelação: ditava a vontade divina que Óláfr regressasse à Noruega, onde ele seria rei para sempre ${ }^{16}$. E Óláfr assim o fez, navegando de volta a França onde, tal como nos diz o poema Víkingarvísur, ele chegou a Poitou e ao rio Loire. A narrativa em prosa da Heimskringla é praticamente a mesma, referindo todos os topónimos entre Hól e Gunnvaldsborg e citando o trabalho poético de Sigvatr Pórðarson. É ainda dito que o nobre Geirfiðr só foi libertado depois da população local pagar um resgate ${ }^{17}$. Também à semelhança do Fagrskinna, é mencionada uma batalha em Karlsá, topónimo que volta a sugerir um curso de água dado o elemento -á (rio ou ribeiro). E conta o texto da Heimskringla que Óláfr queria ir até Gibraltar e de lá para Jerusalém, mas que teve um sonho em que lhe foi dito para regressar à Noruega, onde ele seria monarca perpétuo. E com isso ele regressou a França, a Poitou, onde a narrativa em prosa da saga volta a coincidir com o poema. Tanto no Fagrskinna como na Heimskringla, é dito que Óláfr passou o inverno na Normandia antes de rumar para o norte da Europa ${ }^{18}$.

Nada disto pode ser lido nas fontes ibéricas. O documento de 1018 refere-se aos atacantes como "filhos e netos dos normandos" e diz que entraram no Douro em Julho de 1015, sujeitando a região entre esse rio e o Ave a nove meses de saque (In Era M L iij mense Iulio ingressi fuerunt filius et neptis Lotnimis multis in Doiro, predans et captivans de Doiro in Ave per viiij menses) ${ }^{19}$. Não nos é dito ao certo por onde andaram os piratas nórdicos, nem qual o nome do seu líder. O mesmo é verdade para a notícia contida na Crónica dos Godos, que apenas refere que os vikings atacaram o castelo de Vermoim a 6 de Setembro de 1016 (Era MLIV viii ${ }^{\circ}$ idus septembris veniunt Lormanes ad castelum Vermudii) ${ }^{20}$. Quanto ao documento de 1024 proveniente de Santiago de Compostela, embora a narrativa seja relevante, não é, no entanto, específica ao ponto de nos indicar quem era o líder dos piratas nórdicos. É dito apenas que eles, a gens Leodemanorum, atacaram Tui e mataram ou capturaram muitos dos seus clérigos, incluindo o bispo (eius episcopus qui ibi morabatur cum omnibus suis ab ipisis inimicus captivus ductos est), deixando a cidade num estado deplorável (et ipsam civitatem ad nichilum reduxerunt, que plurimus annis vidua atque lugubris permansit $)^{21}$. Não temos sequer a data exacta dos acontecimentos, mas apenas o ano do documento como terminus ante quem, por ventura recuável dois anos se tivermos em conta a referência a Suero como bispo de Lugo, Mondoñedo, Ourense e Tui, talvez indicando, conforme sugere López Alsina, que já em 1022 a cidade estaria sem prelado próprio e, como tal, deserta ${ }^{22}$.

Ainda assim, tomando todos estes dados em consideração, não é impossível que Óláfr Haraldsson tenha sido responsável por um ou mais ataques no ocidente ibérico. Há uma correspondência geográfica, na medida em que, se chegou a Gibraltar, o

\footnotetext{
16 Fagrskinna, p. 136.

17 Heimskringla, p. 257.

18 Fagrskinna, p. 136; Heimskingla, p. 259.

19 Pinto De Azevedo, "A expedição de Almançor", p. 91.

20 "Chronica Gothorum", p. 9.

21 Lucas Álvarez, Tumbo A, p. 153.

${ }^{22}$ López Alsina, "La cristalización de Tui“, p. 63.
} 
santo norueguês terá naturalmente navegado ao longo da costa galega e portuguesa. E há também a possibilidade de correspondência cronológica, dado que se conhecem notícias de ataques vikings no território no início do século XI. Existe, portanto, uma hipótese, mas o seu valor exacto só pode ser medido mediante uma análise atenta das fontes. Só assim podemos chegar a uma conclusão minimamente assente no registo histórico e sem cairmos no erro de aceitar uma hipótese só porque ela foi defendida por outros estudiosos.

\section{QUANDO}

Comecemos por precisar os acontecimentos no tempo, estabelecendo uma cronologia com base nas fontes nórdicas que, embora não sendo coerentes, contêm ainda assim suficientes referências históricas para estabelecer parâmetros cronológicos.

Segundo o Fagrskinna, quando Óláfr regressou a Inglaterra depois de ter viajado até ao Estreito de Gibraltar e passado o Inverno na Normandia, tinham decorrido catorze anos sobre a morte de um outro Óláfr, apelidado de Tryggvason ${ }^{23}$. Também ele foi rei da Noruega, tendo morrido no ano $1000^{24}$, o que quer dizer que Óláfr Haraldsson terá deixado o rio Sena em 1014. No mesmo sentido vai a Heimskringla ou pelo menos parte dela, dado que o texto contradiz-se várias vezes: segundo o capítulo 16, o norueguês deixou Inglaterra em direcção ao sul da Europa depois da morte do rei Æthelred ${ }^{25}$, o qual faleceu em 1016; no entanto, no capítulo 20 da mesma saga, é dito que tinham passado treze anos desde a morte de Óláfr Tryggvason quando Óláfr Haraldsson chegou à Normandia durante o outono ${ }^{26}$, o que equivale ao ano 1013 . Em sentido diferente vai a Historia Norwegie que, para além de não fazer qualquer referência à Normandia, parece colocar a expedição ibérica por alturas da morte do rei dinamarquês Sveinn tjúguskegg ou Barba Forcada, no início de 1014²7. Se bem que, a ser verdade, isso significa que Óláfr Haraldsson teria viajado durante o Inverno, estação pouco propícia ou mesmo arriscada para a navegação. Mais provável será, por isso, a versão contida nas colectâneas de sagas de reis, que sugere que, se o santo norueguês esteve na Península Ibérica, terá sido o mais tardar em 1013. O que vai de encontro à cronologia geralmente aceite, que faz datar de 1015 o início do seu reina$\mathrm{do}^{28}$, altura em que ele estaria já na Noruega.

Assim sendo, podemos pôr de parte a ideia de que Óláfr Haraldsson atacou o norte de Portugal em 1015 e 1016, por óbvia impossibilidade cronológica. E se ele não liderou os ataques entre os rios Douro e Ave e contra o castelo de Vermoim, restanos o saque de Tui de entre as incursões nórdicas de que temos notícia no ocidente peninsular.

\footnotetext{
23 Fagrskinna, p. 136.

24 KraG, "The creation of Norway", p. 647.

${ }^{25}$ Heimskringla, p. 256.

${ }^{26}$ Ibidem, p. 259.

${ }^{27}$ Historia Norwegie, p. 101.

${ }^{28}$ KRAG, "The creation of Norway“, p. 647.
} 


\section{ONDE}

Podem os locais referidos nas fontes nórdicas ser identificados com povoações ibéricas? E, nesse sentido, pode Tui ou a foz do rio Minho ser um deles?

A tradução dos topónimos nórdicos é uma ferramenta pouco útil na resolução do problema, uma vez que o significado dos nomes não permite uma identificação cabal. Será Gríslupollr um Lago do Porco, de gríss (porco) e pollr (lago, lagoa, charco), referindo-se por ventura a um local de criação de suínos? Ou será o lago de alguém chamado Grísla? Terá Fetlafjörðr o significado de Fiorde das Espadas ou Cintos, de fjörðr e o genitivo plural de fetill (cinto de espada), indicando uma ria ou a foz de um grande rio? Seria Seljupollr um Lago do Salgueiro, de selja e pollr, talvez por ser um sítio com bastantes árvores dessa espécie? Não sabemos. Não é sequer certo que os nomes sejam reflexo de características locais e que não foram inventados por Sigvatr Pórðarson para dar corpo a informação sobre as aventuras de Óláfr Haraldsson. Outra alternativa, que parece ter mais adeptos, é a de que os nomes nórdicos reflectem apenas a fonética de topónimos ibéricos, algo que estará na origem da identificação de Gríslupollr com Castropol, Viljámsbœr com Villamea, Fetlafjörðr com Betanzos ou a Corunha (por via de Farum Brigantium) e Seljupollr com a foz do Minho, ora com base em Cilenorum aqua (supostamente A Guarda), ora por referência ao rio Sil. Semelhança de sons e pouco mais, a que se junta a ideia de que Gunnvaldsborg -a borg (castelo ou fortaleza) de Gunnvald (Gonçalo)- é na realidade Tui, tese defendida no século XIX por Paul Riant ${ }^{29}$. E há que referir ainda a teoria de Lúcio Vidal, que rejeita a localização de Karlsá no sul de Espanha ou a identificação com Alcácer do Sal, sugerindo em alternativa a foz do rio Douro ${ }^{30}$. O que vai contra as teorias dominantes, as quais fazem equivaler o topónimo a Cádis ${ }^{31}$ ou ao Guadalquiviri ${ }^{32}$. Para mais, a tese parte do pressuposto de que Tui é a Gunnvaldsborg das fontes nórdicas, algo que, como veremos, não é certo.

À excepção da teoria de Lúcio Vidal, todas estas hipóteses foram mencionadas por Kristroffer Fabricius em $1892^{33}$ e são hoje comuns em publicações sobre nórdicos na Península Ibérica. São disso exemplo os trabalhos de Hipólito de Sá Bravo ${ }^{34}$, Jaime Alemparte ${ }^{35}$, Singul Lorenzo ${ }^{36}$, Morales Romero ${ }^{37}$ e Suso Vila ${ }^{38}$. Até a mais recente edição do Fagrskinna indica o mesmo que Fabricius ${ }^{39}$ e há ainda que referir com especial destaque a obra de Vicente Almazán, autor de referência no estudo da presença nórdica na Península Ibérica e um adepto da teoria de que Óláfr Haraldsson

29 Riant, Expéditions et pèlerinages, p. 74.

${ }^{30}$ VIdAL, "Olaf Haraldson em Portucale", pp. 49-50.

31 Fagrskinna, p. 316.

32 Heimskringla, 257, nota 2.

33 Kristoffer Fabricius, La connaissance de la Peninsule Espagnole, p. 6.

34 Sá Bravo, Monasterios de Galicia, p. 290.

35 Ferreiro Alemparte, Arribadas de normandos y cruzados, pp. 50-6.

36 Singul Lorenzo, Catoira, p. 52.

37 Morales Romero, Historia de los Vikingos en España, p. 204.

38 VILA, A cidade de Tui, pp. 19-20. Embora Suso Vila admita a dificuldade em fazer coincidir os dados que nos são transmitidos pelas fontes.

39 Fagrskinna, pp. 313-9. 
esteve na Galiza $^{40}$. E isto apesar de nem todos os estudiosos concordarem com essa tese: segundo uma referência do próprio Almazán, data também do século XIX a voz discordante de Unger, responsável por uma edição de 1868 da Heimskringla onde todos os topónimos entre o Hól e o Loire são localizados em França ${ }^{41}$. O próprio Kristoffer Fabricius apresentou dúvidas sobre a ideia de que Óláfr Haraldsson esteve na Península Ibérica ${ }^{42}$ e, mais recentemente, Elisabeth van Houts retomou a hipótese de que a estrofe 11, a que menciona Gríslupollr e Viljámsbor - o bœr (quinta, fazenda) de Viljám (Guilherme) - refere-se a um ataque na Aquitânia, à época governada por Guilherme $\mathrm{V}^{43}$. Ainda assim, não obstante as vozes dissonantes e as ressalvas de alguns autores, muitos seguem o caminho fácil da semelhança fonética ou da tradição académica. Parece haver aquilo a que em inglês se chama wishful thinking ou o desejo de que as coisas sejam realidade, neste caso que Óláfr Haraldsson tenha estado na Galiza. De tal forma que há até quem tenha traduzido várias estrofes do Vikingarvísur de forma questionável, substituindo os topónimos originais por uma suposta equivalência ibérica, como se de um facto se tratasse. Foi o caso de Almazán ${ }^{44}$, cujo (mau) exemplo foi imitado já no século XXI por Araceli Otero Fernández ${ }^{45}$. O que é certamente sinal da convicção de alguns, mas é também algo que esconde uma teoria frágil, na medida em que a tradução apresenta como facto algo que não passa de uma mera hipótese. Porque não obstante o número de autores que durante mais de um século têm vindo a defender a presença de Óláfr Haraldsson na Galiza, disseminando a teoria e tornando-a num facto aos olhos de muitos, a verdade é que os textos medievais não oferecem qualquer certeza. $\mathrm{O}$ que nos leva de volta à pergunta inicial: até que ponto as fontes permitem-nos dizer que Óláfr Haraldsson esteve, de facto, em território ibérico?

Já vimos que os nomes contidos no relato poético dizem pouco ou nada quando à identidade dos locais atacados. Note-se, aliás, que vários deles seguem um padrão que conjuga um nome próprio com uma qualquer característica do terreno: o lago de Grísla (Gríslupollr), a quinta de Guilherme (Viljámsbøer), a fortaleza de Gonçalo (Gunnvaldsborg), a foz ou o rio de Carlos (Karlsóss/Karlsá). E, uma vez mais, não se sabe o porquê deste padrão, se é baseado em elementos dos locais atacados, na fonética de topónimos nativos ou se são apenas nomes criados para dar corpo aos feitos de Óláfr Haraldsson. A única certeza é que são vagos, não permitindo uma identificação conclusiva. Se, por exemplo, Fetlafjörðr corresponde a uma ria ou à foz de um grande rio, isso é uma característica em que encaixam múltiplos locais costeiros. Pensemos na área em redor de La Rochelle, no estuário da Gironda ou na foz do Adour; pensemos em Hendaye ou, passando a fronteira para o lado espanhol, em Pasaia, na ria de Mundaca ou mesmo na de Bilbao. Os topónimos mencionados pelo Vikingarvísur são de tal forma genéricos, que podem ser aplicados a diversos sítios. Não se percebe por isso o porquê de se dizer que Fetlafjörðr é a ria da Corunha ou de

\footnotetext{
40 Almaż́n, Gallaecia Scandinavica, pp. 113-5.

${ }^{41}$ Ibidem, p. 114.

42 Kristoffer Fabricius, La connaissance de la Peninsule Espagnole, p. 4.

43 Jesch, Ships and Men, p. 84.

44 Almaź́n, Gallaecia Scandinavica, p. 113.

45 Otero Fernández, Os viquingos en Galicia, pp. 84-5.
} 
Betanzos. Não há nada, nenhum texto medieval que o indique ou sequer que o sugira de uma forma clara, seja ele nórdico ou ibérico. E a notícia de um ataque viking na região da Corunha em 844 não significa que Óláfr Haraldsson tenha feito o mesmo. Não estamos a falar de autómatos nórdicos programados para investirem apenas contra determinados locais, mas de seres humanos que procuravam lucro fácil, pelo que atacariam qualquer ponto que lhes parecesse propício. Quanto à semelhança fonética, trata-se apenas disso: semelhança. Não só não é prova suficiente, como até pode ser um elemento enganador. Porque a parecença de sons, tal como o significado dos topónimos, pode servir para qualquer hipótese desde que haja uma vaga similitude. Por exemplo, porque é que Seljupollr há-de ser A Guarda ou a foz do rio onde desagua o Sil e não Saint-Palais, em França? Dirão alguns que não há referências a nórdicos nesse ponto específico do território francês, mas também não há nada que indique a presença de Óláfr Haraldsson no rio Minho. Há apenas uma sugestão de sons semelhantes, a notícia de um ataque a Tui algures antes de 1024 (não se sabe liderado por quem) e o desejo de muitos estudiosos de que essa investida tenha sido levado a cabo pelo santo norueguês. Desejo e não provas concretas.

Não adianta, neste ponto, dizer que não se conhecem ataques vikings no País Basco ou na Gasconha no início do século XI e que por isso Oláfr Haraldsson só pode ter estado na Galiza, onde há registo de investidas nórdicas. Dozy, por exemplo, assumiu uma ligação entre a notícia do saque de Tui e as narrativas sobre a expedição do santo norueguês ${ }^{46}$. Mas fazê-lo é ignorar que a informação de que dispomos hoje são apenas fragmentos que escaparam ao desgaste do tempo ou aos azares da História. Não temos, por outras palavras, um registo completo e detalhado da actividade viking, mas apenas os pedaços de informação que sobreviveram até aos nossos dias. E mesmo esses referem-se apenas ao que foi registado, dado que terão havido ataques dos quais não se fez notícia escrita. O que quer dizer que as referências documentais de que dispomos não têm que estar necessariamente relacionadas: tanto podem ser fragmentos sobre as actividades de um único bando de piratas, como podem ser notícias sobre as acções de diferentes grupos activos em simultâneo numa mesma região. Regra geral, não temos dados suficientes para dizê-lo ao certo. Assim sendo, a referência escrita ao ataque a Tui não prova que Óláfr Haraldsson esteve na Galiza (pode ter sido qualquer outro nórdico), tal como a falta de informação sobre investidas vikings na Gasconha no início século XI não é suficiente para afirmar que o rei norueguês não atacou a região, dado que pode tê-lo feito sem que o registo escrito tenha sobrevivido até aos nossos dias.

Mas não é Gunnvaldsborg o mesmo que Tui, conforme defendeu Paul Riant e tantos outros? A pergunta verdadeiramente pertinente é outra: qual é a base dessa identificação? A teoria assenta em três pontos, nomeadamente a ideia de que Seljupollr é a foz do rio Minho, que Tui estaria sob a protecção de alguém chamado Gonçalo e o conhecimento de que a cidade foi atacada no início do século XI. Ora, já vimos que a identificação de Seljupollr com A Guarda é frágil, baseada que está apenas na semelhança de sons; para mais, a tese depende da própria correspondência entre Tui e Gunnvaldsborg: se esta última é a cidade tudense, então Seljupollr deve ser a foz do Minho e vice-versa, o que é um argumento circular. Também conforme vimos e

46 Dozy, Recherches, p. 323. 
ao contrário do que faz crer Dozy, a notícia de um ataque em território galego antes de 1024 não é, por si só, prova das acções de Óláfr Haraldsson, dado que ele não é referido no documento e temos apenas informação fragmentada. O que deixa à tese que identifica Tui com Gunnvaldsborg um único argumento: o de que a cidade estaria sobre a protecção de alguém chamado Gunnvald ou Gonçalo. Mas quem ao certo?

Lúcio Vidal pergunta se será o Gonçalo Sanches que derrotou os vikings de Gunderedo em $969^{47}$, o que me parece francamente impossível, não só por causa do hiato temporal, mas porque não se sabe ao certo quem era o conde que venceu os invasores nórdicos no século X. Conhece-se apenas o estatuto social e o nome. Pérez de Urbel sugeriu mesmo que se tratava de um nobre de além-Pirenéus em peregrinação a Santiago de Compostela ${ }^{48}$. E, para mais, segundo a Crónica de Sampiro conforme preservada na História Silense, que é a fonte mais antiga de que dispomos para informação sobre a expedição de Gunderedo, o conde que derrotou os vikings chamava-se Guilherme e não Gonçalo (Comes namque Guillelmus Sancionis) ${ }^{49}$. Ainda segundo Lúcio Vidal, ao analisar as opiniões de Almázan e de Fernández Romero, o jarl Geirfiðr podia ser um arcediago Gaufido, supostamente colaborador de Gelmírez e embora seja notado que o Geirfiðr de 1114 não podia ter colaborado com o primeiro arcebispo de Compostela ${ }^{50}$. Além disso, não é certo que um vigário geral pudesse ser entendido como um jarl ou nobre pelos nórdicos. Outra hipótese é a sugerida por López Alsina, que refere Mendo Gonçalves, conde de Portucale ${ }^{51}$, o que significa que o topónimo contido nas fontes nórdicas estaria baseado não num nome próprio, mas num patronímico. Mas a teoria esbarra na morte de Mendo Gonçalves, falecido em 1008, segundo a Crónica dos Godos ${ }^{52}$, o que quer dizer que Óláfr Haraldsson teria que ter estado em Tui antes dessa data, afastando-o em cinco anos de 1013, altura em que passou o inverno na Normandia. Para mais, há que considerar ainda a discrepância narrativa, na medida em que as fontes nórdicas falam da captura e resgate de um jarl ou conde, enquanto o documento de 1024 refere a captura ou morte do bispo de Tui.

Numa tentativa de resolver este problema, López Alsina sugere a necessidade de se adicionar o cativeiro do aristocrata ao do prelado se se assumir que os relatos são complementares $^{53}$. Uma assunção que me parece desprovida de base pelos motivos já referidos e que repito: a identificação tradicional dos topónimos contidos nas fontes nórdicas é, na melhor das hipóteses, frágil; o documento de 1024 não refere Óláfr Haraldsson; o facto de termos apenas fragmentos de informação sobre a actividade

47 Vidal, "Olaf Haraldson em Portugal", p. 45, nota 6. Acrescente-se que Lúcio Vidal coloca a derrota de Gunderedo em 982, o que é um erro, dado que a Crónica de Sampiro refere que os nórdicos foram expulsos no terceiro ano. Será, supostamente, o terceiro do reinado de Ramiro III, isto é, 969, embora também se possa ler como o terceiro ano desde o desembarque de Gunderedo, que teve lugar em 968. Em qualquer dos casos, 982 é a data errada.

48 "Los primeros siglos de la Reconquista", pp. 153-4.

49 Sampiro, p. 341.

50 VIDAL, "Olaf Haraldson em Portugal", p. 45, nota 10.

${ }^{51}$ López AlsinA, "La cristalización de Tui”, pp. 61-2.

52 "Chronica Gothorum", p. 9. Acrescente-se que a morte de Mendo Gonçalves é por vezes atribuída aos vikings, algo que carece de base histórica, uma vez que não é referido na crónica.

${ }^{53}$ López Alsina, "La cristalización de Tui", p. 62. 
viking na Península Ibérica impede-nos de afirmar com certeza que há uma ligação entre as diferentes narrativas.

Assim sendo, está longe de ser certo que Gunnvaldsborg corresponda à cidade de Tui, dado que a identificação carece de base sólida. E, desse modo, torna-se igualmente difícil aceitar a teoria de Lúcio Vidal que faz equivaler Karlsá ao rio Douro, uma vez que a ideia depende da noção de que Tui foi atacada antes da chegada de Óláfr Haraldsson ao "rio de Carlos". Aliás, do mesmo modo que Elisabeth van Houts sugere que a quinta de Guilherme ou Viljámsbøer estava localizada na Aquitânia de Guilherme V, não é impossível que Karlsá corresponda a um local em França, onde Carlos é um nome próprio com mais tradição do que na Península Ibérica. Mas tudo isto parte do pressuposto de que Óláfr Haraldsson esteve em território ibérico, sendo que a presença do rei norueguês no sul de Espanha pode ser posta em causa por via de uma leitura crítica das fontes nórdicas.

\section{O REI SANTO}

A ascensão de Óláfr Haraldsson ao trono norueguês em 1015 representou mais do que uma ruptura religiosa com o seu antecessor, o jarl Hákon, magnata da região de Trøndelag e um devoto do politeísmo tradicional nórdico. Foi também um acto de emancipação política, na medida em que Hákon mantinha um laço de fidelidade nominal com os reis da Dinamarca, que há muito reclamavam autoridade sobre território norueguês ${ }^{54}$. A experiência independentista foi interrompida em 1028, quando Knútr -conhecido entre nós como Canuto, o Grande- enviou um exército para a Noruega e reintegrou o país na esfera de influência dinamarquesa. Óláfr Haraldsson foi forçado a exilar-se, tentando um regresso ao trono em 1030, tentativa essa que resultou na sua derrota e morte na batalha de Stiklestad.

Não estamos por isso a falar de uma figura qualquer, de apenas mais um rei ou de mais um santo: Óláfr Haraldsson é uma personagem fundacional na História da Noruega! Não só por ter desafiado as pretensões dinamarquesas e sido um mártir dessa luta, mas também porque foi o derradeiro evangelizador e antepassado dos reis noruegueses que lhe sucederam cinco anos depois de Stiklestad, os quais concluíram a unificação do país. Porque chegado o ano de 1035, data da morte de Knútr, a Noruega afastou-se uma vez mais da autoridade dinamarquesa e colocou no trono Magnús, o Bom, ao qual sucedeu Haraldr Harðráđi, filho e meio irmão de Óláfr Haraldsson, respectivamente. Para isso terá contribuído não apenas o contexto político e a legitimidade de sangue, mas também o estatuto de descendentes do santo padroeiro da Noruega. E o culto terá começado muito cedo, praticamente um ano depois da sua morte, quando o corpo de Óláfr Haraldsson, excepcionalmente bem preservado, foi transladado para a igreja de S. Clemente, em Trondheim ${ }^{55}$. As décadas seguintes aumentaram-lhe a fama e os relatos de milagres, ao mesmo tempo que a identidade e independência norueguesas eram consolidadas. A Noruega afirmava-se como um reino no seio da comunidade cristã, devidamente provido de uma figura fundacional

54 KRAG, "The creation of Norway", p. 647.

55 Christiansen, The Norsemen, p. 155. 
que era também santo padroeiro e intercessor divino do país. E é com isto em mente que devemos recordar as considerações sobre, por um lado, as diferentes narrativas nórdicas e, por outro, o processo de transmissão da poesia skáldica.

Conforme foi dito, os capítulos 17 e 18 da Saga de São Olavo, na Heimskringla, não são um texto unitário, dado que não foram escritos por inteiro num dado momento por um único autor. Tratam-se sim da junção de diferentes relatos: um poético, datado do início do século XI; outro em prosa, escrito por volta de 1230 e talvez com origens em ou influências de prosimetra mais antigos. Este facto aconselha uma leitura separada das duas narrativas para se perceber até que ponto elas coincidem e como é que o texto da saga ganhou a sua forma actual. E fazendo-o, apercebemo-nos da dissonância entre o relato poético do Vikingarvísur e a prosa contida no Fagrskinna e na Heimskringla: enquanto as duas colectâneas de sagas de reis colocam o santo norueguês perto da entrada do Mediterrâneo, o poema de Sigvatr Pórðarson não faz qualquer referência a Gibraltar e centra a acção em França. E um facto que o Vikingarvísur tal como o conhecemos hoje está incompleto, pelo que uma presença no sul de Espanha podia, eventualmente, estar relatada em estrofes perdidas. Mas não deixa de ser significativo que, segundo a narrativa em prosa, após lhe ser dito para regressar à Noruega, Óláfr Haraldsson não tenha saqueado a Península Ibérica enquanto navegava de volta ao norte. Em vez disso, é-nos dito que ele deu meia volta em Gibraltar, impulsionado pelo sonho e, saltando a costa ibérica, fica-se por actividade pirata em território francês. Nas palavras de Lúcio Vidal, Óláfr regressou a norte "parece que com pouca pressa" $" 56$.

Esta espécie de regresso a norte a duas velocidades, ora tão rápido que ignora a Península Ibérica, ora tão lento que afinal retoma as pilhagens em França, sugere que a ida a Gibraltar é uma interpolação que cortou a meio o relato da temporada de saque na costa francesa, quebrando a sequência narrativa. E, assim sendo, sugere também que o episódio terá sido trabalhado ao longo do tempo, resultando numa sucessão de eventos pouco coerente. Os traços lendários são aliás óbvios, principalmente na Heimskringla, onde ficamos a saber que Óláfr queria navegar até Jerusalém e que só não o fez porque lhe foi dito para regressar à Noruega, onde seria rei para sempre. É graças a este elemento que se supõe que ele esteve na Galiza, por óbvia necessidade de navegar pela costa ibérica para chegar à entrada do Mediterrâneo. Mas este é também um momento narrativo marcadamente ideológico, na medida em que a noção de rei perpétuo da Noruega resume um ideal político e religioso. Porque se se é monarca por vontade divina -e o sonho assim o indica- então isso legitima o direito de Óláfr a governar, direito seu e dos seus descendentes e que é reforçado pela perpetuidade do título régio, revelando o seu estatuto de padroeiro do reino norueguês. O que ao mesmo tempo deslegitima as pretensões dos reis dinamarqueses sobre a Noruega. Encontramos a mesma ideia no século XII, na Historie Norwegie (Olavum perpetuum regem Norwegie $)^{57}$, e também numa carta de privilégio redigida por volta de 1163 , onde Magnús V reconhece o território norueguês como um feudo de São Olavo e jura administrá-lo enquanto representante e vassalo do rei santo ${ }^{58}$. Já em 1032 contava-se

\footnotetext{
56 Vidal, "Olaf Haraldson em Portucale", p. 46.

57 Historia Norwegie, p. 86.

58 Ibidem, p. 209.
} 
como Óláfr continuou a governar depois da sua morte ${ }^{59}$, o que quer dizer que a noção de monarca perpétuo da Noruega data de pouco depois da batalha de Stiklestad e que o desenvolvimento da ideia coincidiu, por um lado, com a afirmação da independência do país e, por outro, com o período de transmissão do Víkingarvísur até à sua preservação nas colectâneas do século XIII. Caso para perguntar, assim sendo, se a narrativa que encontramos nas sagas de reis não foi influenciada por esse furor patriótico e religioso dos séculos XI e XII. Porque, conforme foi dito, é possível que o poema de Sigvatr Pórðarson tenha sido preservado como um prosimetrum e circulado entre contadores de histórias e as suas audiências, que não estariam imunes ao contexto dos seus dias e podem ter expandido a narrativa, acrescentado ao relato poético original detalhes lendários em prosa que engrandeciam a figura de São Olavo. O que não tem nada de espantoso se considerarmos como, ainda hoje, circulam lendas e narrativas populares sobre personagens históricas, muitas vezes sem fundamento documental, mas que mesmo assim misturam-se com factos. E um desses detalhes acrescentados ao Víkingarvísur pode ter sido precisamente a viagem de Óláfr Haraldsson até ao Estreito de Gibraltar.

Por outras palavras, a presença do santo norueguês na Península Ibérica ou, pelo menos, na Galiza, pode nunca ter acontecido e ser apenas fruto do enfabulamento da narrativa poética por via, por um lado, da transmissão do poema como um prosimetrum durante os século XI e XII e, por outro, do ambiente político-religioso da época, que foi uma altura de afirmação crescente tanto do culto de São Olavo, como da independência da Noruega. Daí que a Heimskringla fale do desejo de navegar até Jerusalém, sinal da piedade cristã de Óláfr, e daí também o sonho que confirmava o seu estatuto de rei perpétuo da Noruega, ideia ideologicamente carregada e datada de pouco depois da morte do monarca. O que temos nas colectâneas de sagas de reis será, portanto, uma narrativa expandida, interpolada, em que ao relato poético original acrescentaram-se elementos hagiográficos. E assim se explica também a discrepância nas linhas do Fagrskinna e da Heimskringla, onde uma temporada de pirataria em França é interrompida por uma viagem até Gibraltar que não provoca nenhuma ida imediata para a Noruega, mas apenas um regresso à pilhagem em território francês e como se nada tivesse acontecido mais a sul. Porque a narrativa original, a poética, talvez se focasse apenas em território francês, enquanto a viagem até à entrada do Mediterrâneo será uma interpolação lendária, um acrescento político-religioso feito durante o processo de transmissão do poema e que enuncia a santidade e estatuto régio de Ólafr Haraldsson.

Esse acrescento faria já parte das histórias sobre São Olavo em circulação no século XII, uma vez que a Historie Norwegie também refere a ida do rei norueguês à Península Ibérica e embora sem indicar quaisquer locais em concreto ${ }^{60}$. E durante o século XIII, os autores do Fagrskinna e da Heimskringla encarregar-se-iam de cristalizar a fusão da poesia com a lenda, dando origem à narrativa aparentemente unitária que hoje conhecemos e que leva tantos a falar de como Tui foi pilhada pelo santo norueguês.

\footnotetext{
59 Ibidem, p. 210.

${ }^{60}$ Historie Norwegie, p. 101.
} 


\section{CONCLUSÃO}

Os topónimos referidos no Víkingarvísur, de Gríslupollr a Gunnvaldsborg, são difíceis de localizar. Assumindo que não foram inventados por Sigvatr Pórðarson, o significado dos nomes parece referir-se a características vagas, passíveis de serem associadas a inúmeros sítios.

Isto contraria a certeza com que é muitas vezes encarada a teoria tradicional que, desde o século XIX, tem defendido a localização dos topónimos na Galiza, teoria essa baseada na similitude fonética e no facto de terem ocorrido ataques vikings no noroeste peninsular no início do século XI. Mas sons parecidos podem ser apenas isso -semelhança e nada mais- e as fontes ibéricas sobre a actividade dos piraras nórdicos são demasiado vagas para permitirem identificar de forma clara a expedição de Óláfr Haraldsson. No caso concreto do ataque a Tui, registado num documento galego de 1024, não nos é dita nem a data exacta da investida, nem quem a liderou. E a correspondência cronológica é vaga, dado que apenas temos dois termini ante quem, o de 1024 e o de 1013, data em que Óláfr chegou à Normandia, não sendo suficiente para provar que o santo norueguês foi responsável pelo ataque a Tui. Para mais, é preciso ter em mente que, no que diz respeito à actividade viking na Península Ibérica, temos apenas fragmentos de informação sobrevivente. Não dispomos um registo completo e detalhado dos ataques nórdicos, pelo que diferentes notícias cronologicamente próximas tanto podem referir-se às actividades de um grupo, como de vários. $\mathrm{O}$ que quer dizer que, dada a falta de informação no documento galego de 1024, o ataque a Tui tanto pode ter sido levado a cabo por Óláfr, como por qualquer outro nórdico cujo nome desconhecemos. E de nada adianta referir que as fontes ibéricas dariam naturalmente destaque às acções de um monarca nórdico, porque, à época, Óláfr era apenas um viking como qualquer outro. Tudo isto, é claro, assumindo que ele esteve de facto no sul de Espanha e que a viagem até ao extremo sul da Europa não é apenas um enfabulamento posterior do poema.

O único motivo pelo qual se crê que Óláfr Haraldsson esteve na Península Ibérica é facto de as sagas de reis colocarem-no junto ao Estreito de Gibraltar, levando à inevitável conclusão de que ele terá navegado ao longo da costa ibérica. Mas esse ponto da viagem não faz parte da narrativa mais antiga, que é a do poema Víkingarvísur, ou pelo menos não do poema tal como o conhecemos hoje. É apenas na prosa de século XIII das sagas de reis que nos deparamos com essa informação que, para mais, é marcadamente ideológica, tanto a nível político como religioso: por um lado, demonstra a piedade cristã de Óláfr pelo seu desejo de ir a Jerusalém e, por outro, afirma o seu direito perpétuo ao trono norueguês, devidamente sancionado por uma relevação divina e passível de ser transmitido aos seus descendentes. O que terá sido certamente útil durante a consolidação da independência da Noruega, que se fez lado a lado com a popularidade crescente do culto de São Olavo. Ora, a transmissão do Víkingarvísur até à sua inclusão nas sagas de século XIII coincidiu com esse período de afirmação política e religiosa norueguesas, abrindo a possibilidade de à narrativa poética terem sido apendiceadas lendas e contos sobre o rei santo. O que ajudaria a explicar não só a referência a Óláfr como rei perpétuo da Noruega, presente tanto na Heimskringla como no Fagrskinna, 
mas também a narrativa desconexa de ambos os textos, onde a actividade pirata em França é interpolada pela viagem ao sul de Espanha.

É um facto que não se conhece a dimensão original do Vikingarvísur, o que quer dizer que também não se sabe qual seria o conteúdo de estrofes eventualmente perdidas. Talvez incluíssem informação sobre uma viagem até ao Estreito de Gibraltar ou talvez indicassem mais locais identificáveis em território francês. Não há como sabê-lo e o que aqui se defende não passa, em última análise, de uma hipótese, passível de ser questionada. Mas as sagas de reis apresentam sinais de uma interpolação, não só pela presença do elemento lendário e ideológico, mas também pela quebra da sequência narrativa, dado que actividade pirata em França é interrompida por uma viagem ao sul de Espanha para depois regressar, num salto, ao saque na costa francesa. Trata-se de uma desconexão hagiográfica que sugere que o episódio de Gibraltar deve ser encarado com cautela ou mesmo posto em causa. E se, como eu proponho, a presença de Óláfr no sul de Espanha é uma lenda tardia, acrescentada à narrativa poética durante os séculos XI ou XII, então não podemos assumir que topónimos como Gríslupollr ou Seljupollr correspondem a locais na Galiza. Talvez devam ser todos localizados em França, quando muito nas regiões em redor dos Pirenéus, dado que é em território francês que se encontram os locais mencionados antes e depois dos versos que referem os sítios sob debate. E, assim sendo, Óláfr Haraldsson não terá estado nem em Tui, nem em Gibraltar.

\section{BIBLIOGRAFIA}

AlmazÁn, Vicente, Gallaecia Scandinavica: introducción ó estudio das relacións Galaico/Escandinavas durante a Idade Media, Vigo: Galaxia, 1986.

Andersson, Theodore M., "Kings' Sagas (Konnungasögur)", in Carol L. Clover e John Lindow (eds.), Old Norse-Icelandic Literature: a critical guide, Toronto: University of Toronto Press, 2005, pp. 197-238.

Christiansen, Eric, The Norsemen in the Viking Age, Oxford e Malden: Blackwell, 2006 (2 $2^{\mathrm{a}}$ edição).

"Chronica Gothorum", ed. Alexandre Herculano, in Alexandre Herculano (ed.), Portugaliae Monumenta Historica: Scriptores I, Lisboa: Typis Academicis, 1856, pp. 5-17.

Dozy, Reinhart, Recherches sur l'Histoire et la Literature de l's Espagne pendant le Moyen Age, II, Leyde: Brill, 1860 (2 edição).

Fagrskinna: a catalogue of the kings of Norway, ed. Alison FINLAY, Leiden e Boston: Brill, 2004.

Ferreiro Alemparte, Jaime, Arribadas de normandos y cruzados a las costas de la Península Ibérica, Madrid: Sociedad Española de Estudios Medievales, 1999.

Frank, Roberta, "Skaldic Poetry", in Carol L. Clover e John Lindow (eds.), Old Norse-Icelandic Literature: a critical guide, Toronto: University of Toronto Press, 2005, pp. 157-196.

Heimskringla: History of the kings of Norway, ed. Lee M. Hollander, Snorri Sturluson. Austin: University of Texas Press, 1999 (3 ${ }^{\mathrm{a}}$ edição). 
Historia Norwegie, eds. Inger Ekrem, Lars Boje Mortensen, trad. Peter Fisher, Copenhaga: Museum Tusulanum, 2003.

JESCH, Judith, Ships and Men in the Late Viking Age: the vocabulary of runic inscriptions and skaldic verse, Woodridge: Boydell, 2008 (2 edição).

Krag, Claus, "The creation of Norway", in Stefan Brink e Neil Price (eds.), The Viking World, Londres e Nova Iorque: Routledge, 2010 (3ª edição), pp. 645-651.

Kristoffer Fabricius, Adam, La connaissance de la Péninsule Espagnole par les homes $d u$ Nord, Lisboa: Imprensa Nacional, 1892.

López Alsina, Fernando, "La cristalización de Tui como espácio de poder señorial entre 1095 y 1157", in Silvia GonzÁlez Soutelo e Marta CEndón Fernández (coords.), Tui, presente, pasado y futuro: I Coloquio de Historia de Tui, Pontevedra: Diputación de Pontevedra, 2006, pp. 57-95.

Lucas Álvarez, Manuel (ed.), Tumbo A de la Catedral de Santiago, Santiago de Compostela: Seminario de Estudos Galegos, Cabildo de la S.A.M.I. Catedral, 1998.

Morales Romero, Eduardo, Historia de los Vikingos en España: ataques e incursiones contra los reinos cristianos y musulmanes de la Península Ibérica en los siglos IX-XI, Madrid: Miraguano, 2006 ( $2^{\mathrm{a}}$ edição).

Otero Fernández, Araceli, Os Viquingos en Galicia: mito e realidade, A Coruña: Hércules, 2002.

Pérez De Urbel, Frei Justo, "Los Primeiros siglos de la Reconquista (Años 7111038)" in Historia de España Menéndez Pidal, volume 6: España Cristiana -comienzo de la Reconquista (711-1038), dir. José María Jover Zamora, $6^{\mathrm{a}}$ edição, Madrid: Escalpe-Calpe, S.A., 3-348.

Pinto De Azevedo, Rui, "A expedição de Almançor a Santiago de Compostela em 997, e a de piratas normandos à Galiza em 1015-16", in Revista Portuguesa de História, Tomo 14, Coimbra: Instituto de Estudos Históricos, 1973, pp. 73-93.

Riant, Paul, Expéditions et pélerinages des Scandinaves en Terre Sainte au temps des Croisades, Paris, 1865.

SÁ Bravo, Hipólito, Monasterios de Galicia, Madrid: Everest, 1983.

Sampiro: su crónica y la monarquia leonesa en el siglo X, ed. Justo Pérez de Urbel, Madrid: Escuela de Estudios Medievales, 1952.

Singul Lorenzo, Francisco Luis, Catoira: chave e selo de Galicia, Catoira: Concello de Catoira, 1999.

The Gesta Normannorum Ducum of William of Jumièges, Orderic Vitalis, and Robert of Torigni, volume 2: Books V-VIII, ed. Elisabeth vaN HouTs, $2^{\mathrm{a}}$ edição, Oxford: Oxford University Press, 2003.

Vikingarvisur: http://abdn.ac.uk/skaldic/m.php?p=text\&i=1360 [consultado a 23-04-2014]

VIDAL, Lúcio A., "Olaf Haraldson em Portucale (Notas a dois artigos sobre as sagas nórdicas e a Hispania" in Grial, Tomo 21, número 79, 1983, pp. 43-52.

VILA, Suso, A cidade de Tui durante a Baixa Idade Média, Noia (A Coruña): Toxosoutos, 2009. 